\title{
Survival and Senescence of Human Young Red Cells in Vitro
}

\author{
Angela Risso ${ }^{a}$ Annarita Ciana ${ }^{b}$ Cesare Achillib ${ }^{b}$ Giampaolo Minetti ${ }^{b}$
}

aDepartment of Agriculture and Environment Sciences, University of Udine, Udine, bLaboratories of Biochemistry, Department of Biology and Biotechnology, University of Pavia, Pavia, Italy

\section{Key Words}

Red cells • Lifespan • Erythropoietin • Survival • Neocytolysis

\begin{abstract}
Background: A number of experimental investigations in vivo suggest that in humans a decrease of circulating erythrocyte number ensues whenever erythropoietin (EPO) plasma level decreases. Since the process seems to selectively eliminate young red cells (neocytes), it has been named neocytolysis. The experimental models in vivo have revealed and documented multiple forms of neocytolysis but have not fully elucidated the specificity of the target red cells and the relation with EPO level changes. In an attempt to better characterize the neocytolytic process, we have undertaken an in vitro investigation on age-ranked human red cells. Methods: By centrifugation on Percoll density gradient we separated the red cells population into three subsets, neocytes, middle-aged and old. Then we comparatively investigated the kinetics of survival of the subsets cultured under different conditions: with medium alone, with $10 \%$ autologous plasma, with EPO, alone or in combination with autologous monocytes. Results: Neocytes showed a viability and a survival rate lower than the other red cells when cultured in medium or with $10 \%$ plasma. EPO at physiological doses increased their survival rate, but not that of the other subsets. This effect was enhanced by co-culture with monocytes. Conclusion: Likely neocytes are more sensitive than the other RBCs subsets to presence or absence of survival signals, such as EPO or plasma or monocytes derived factors. These observations could provide an insight into the link between the decrease in EPO plasma level and the reduction of circulating red cells mass and account for the specificity of neocytes clearance
\end{abstract}

Copyright $\odot 2014$ S. Karger AG, Basel

\section{Introduction}

The lifespan of human red blood cells (RBCs) has been the subject of several studies both in vivo and in vitro. The in vivo studies outlined the red cell lifespan of about 100-120 
days that is ended by a process of senescence leading to the clearance from the peripheral blood [1].

Changes in lifespan have been observed either as the result of pathological condition, like in beta thalassemia or sickle cell disease [2,3] or as a physiological adaptive response to particular environments, requiring a fast decrease in circulating red cells mass [4-6]. While the pathological variation of RBC lifespan has received much interest because of obvious medical implications, less is known about the cellular and molecular mechanisms underlying erythrocyte demise over physiological adaptive responses, although investigations have been made on different human experimental models. In high altitude polycythemic dwellers returning to a normoxic environment, a fast decrease in RBC mass is obtained by a decrease in EPO synthesis and by destruction of red cells [5, 6]. A similar process occurs also in astronauts to alleviate the "pseudopolycythemia" that ensues over the first days in low gravity, due to a fast redistribution of blood from lower body to thorax and reduction of plasma volume [7, 8]. An association between erythrocyte clearance and EPO decrease has been found also in patients affected by renal failure, where impairment of kidney function affects EPO production $[9,10]$, and in healthy human subjects where EPO variations are artificially induced as in blood doping [11].

This process seems to cause a selective death of young red cells or neocytes as shown by analysis of blood samples drawn from high altitude acclimatized people upon return to sea level, astronauts or anemic uremic patients [4-7, 10,12], hence it has been named "neocytolysis".

This hypothesis, i.e. a selective elimination of neocytes associated to decrease in EPO levels, would account for a fast change of RBC mass but some critical issues are still waiting for an explanation, as indicated by an overview of the topic recently published [13]. It should be mentioned that the in vivo experimental models are sometimes affected by problems due to the methodological procedure (lack of investigation on objective markers of red cells age) or the intrinsic variability of the adaptive responses displayed by human subjects, that would require a larger number of individuals than those is normally possible to examine [13]. In fact, whereas red cell death in association with decrease of EPO was observed in all the experimental models mentioned above, and it was prevented by EPO administration over deacclimatization from high altitude [5], neither the identification of neocytes as specific targets of neocytolysis nor the causal relationship between EPO decrease and neocyte clearance have been fully elucidated.

At the cellular level, Trial et al. observed that EPO withdrawal from human splenic endothelial cells (HSECs) cultured in vitro, was associated with an increase in membrane permeability and with changes in interactions between HSECs, macrophages and neocytes, thereby suggesting that this could lead to macrophage mediated ingestion of neocytes [14]. Accordingly, both in astronauts, over the first days of spaceflight, and in mountain climbers, over the deacclimatization from high altitude, neocytes showed a "senescent-like" phenotype and externalisation of phosphatidylserine (PS) $[6,12]$ and this phenotype could lead to phagocytosis by macrophages.

In search of an experimental system which could possibly provide some clues to address the issues above mentioned, we have compared the survival kinetics of age-related red cells subsets, namely young, middle aged and old erythrocytes, in vitro incubated under different culture conditions, and the effect of the addition of EPO to the culture medium.

\section{Materials and Methods}

\section{Materials}

All chemicals and reagents were of analytical grade and, unless otherwise specified, were purchased from Sigma (St. Louis, MO, USA). 


\section{Red cell preparation and culture}

Blood samples from healthy donors were provided by the local blood bank of "Santa Maria della Misericordia" Hospital, collected in Vacutainer ${ }^{\circledR}$ (Becton-Dickinson, CA, USA) with K-EDTA as anticoagulant and processed soon after blood withdrawal. The study was done in compliance with the Declaration of Helsinki as revised in 2008 and all donors gave an informed consent to blood donation.

To separate platelet depleted plasma, aliquots of blood samples were centrifuged at $750 \mathrm{~g}$ for $10 \mathrm{~min}$ and the supernatant was centrifuged twice at $1000 \mathrm{~g}$ for $20 \mathrm{~min}$ to remove any remaining cells and platelets.

The erythrocytes were separated from blood samples by filtration on a mixture made of equal parts, by weight, of $\alpha$-cellulose and microcrystalline cellulose equilibrated with PBS (5 mM Na-phosphate, $154.5 \mathrm{mM}$ $\mathrm{NaCl}, 4.5 \mathrm{mM} \mathrm{KCl}, \mathrm{pH}$ 7.4) [15]. The red cells, purified from leukocytes and platelets by the filtration, were washed three times with PBS before use.

To separate age-related subsets of red cells, a RBC suspension at $25 \%$ Hct was layered onto a discontinuous Percoll ${ }^{\mathrm{TM}}$ gradient solution, made in a $15 \mathrm{ml}$ sterile tube with densities ranging from 1.052 to $1.117 \mathrm{~g} / \mathrm{ml}$ and centrifuged at $1075 \mathrm{~g}$ for $20 \mathrm{~min}$, according to a procedure already described [6].

The centrifugation resolved the cell suspension into four subsets: three distinct bands of cells of low, middle, and high density [density (d): 1.091, 1.104 and $1.117 \mathrm{~g} / \mathrm{ml}$, respectively] and a very thin band of red cells floating above the low density RBCs (density range: 1.078-1.091 g/ml) including the majority of reticulocytes [6]. The percentage of reticulocytes contaminating the low density red cells was lower than $6 \%$, as assessed by flow cytometry analysis of red cells treated with fluorescein isothyocyanate conjugated anti CD71 monoclonal antibody (Becton-Dickinson, San Diego, CA, USA) or stained with thyazole orange. Aliquots of age ranked cells were cultured at $37^{\circ} \mathrm{C}$ in a $\mathrm{CO}_{2}$ incubator, in 96 microwell plates (Euroclone, Italy), at a density of $5 \times 10^{6} / \mathrm{ml}$ either in RPMI 1640 (Euroclone, Italy), supplemented with $5 \mathrm{mM}$ glucose and $1 \mathrm{mM}$ glutamine or in the same medium with $10 \%$ autologous platelet-depleted plasma. Cell counts in the RBC subsets recovered from the cultures were obtained by microscopy inspection with a haemocytometer. In each sample the counting of the intact cells was repeated three times.

To separate mononuclear leukocytes, aliquots of blood samples were centrifuged through a FicollHypaqe density gradient at $800 \mathrm{~g}$ for $20 \mathrm{~min}$. A negative selection of monocytes was performed by depletion of CD3 and CD19 positive cells with CD3 and CD19 microbeads (Miltenyi, Biotec GmbH, Bergish Gladbach, Germany), through immunomagnetic separation. The CD3- CD19- cells eluted from the Magnetic Separation column were $95 \%$ CD14 positive, as shown by flow cytometry analysis. They were incubated at a density of $2,5 \times 10^{6} / \mathrm{ml}$ in microwells for $120 \mathrm{~min}$ at $37^{\circ} \mathrm{C}$ in medium supplemented with $10 \%$ autologous plasma. The few non adherent cells were discarded by washing twice the microwells with RPMI. The microscopy inspection ensured that no floating cells over adherent cells were still detectable.

This separation procedure was preferred to the positive selection of mononuclear lymphocytes by CD14 microbeads, in order to avoid the perturbation of the monocyte cell membrane resulting from the interaction between CD14 and the microbead-linked anti-CD14 antibody.

Supernatants from adherent cells were harvested from the cultures after $36 \mathrm{~h}$ of incubation in RPMI medium enriched in $10 \%$ platelet-depleted autologous plasma, glucose and glutamine as above described. Serial dilutions of human recombinant erythropoietin alpha (Eprex, Jansenn-Cilag Ab, Sweden) were made in the same medium from a solution containing $4000 \mathrm{IU} / \mathrm{ml}$.

\section{Flow cytometry assays}

Aliquots (0.5-1 $1 \times 10^{6}$ cells) of each RBC subset were assayed for the expression of the membrane proteins CD55, CD47 and CD59, according to a standard method, by means of the Facscalibur cytometer equipped with a 15mW $488 \mathrm{~nm}$ Argon ion laser and the Cell Quest software (Becton-Dickinson). Anti-human CD47 (mouse IgG2b,k) and anti-CD59 (mouse IgG2a,k) fluorescein isothyocyanate (FITC)-conjugated and anti-human CD55 (mouse IgG1,k) were purchased from DBA (Santa Cruz, CA, USA). FITC-conjugated F(ab)'2 polyclonal antibody anti mouse Immunoglobulins was from Euroclone (Devon, UK). Irrelevant, isotype-matched mouse monoclonal antibodies from our laboratory were used as negative controls. To detect PS exposure, RBCs were treated with FITC-annexin V (DBA) with the procedure suggested by the manufacturer, then they were immediately analysed by flow cytometry. For the viability assay, aliquots $\left(1-0.5 \times 10^{6}\right)$ of each RBC subset were loaded with $5 \mu \mathrm{M}$ calcein-AM (Invitrogen, CA, USA) by a method described in [16] and examined by flow cytometry. Their fluorescence intensity was compared to that of erythrocytes permeabilized with 0.5\% saponin in PBS. To detect Bcl-xl and Bak, red cells were fixed with $4 \%$ formaldehyde in PBS for 30 
min, centrifuged, resuspended in ice cold PBS containing $0.05 \%$ glutaraldehyde for $30 \mathrm{~s}$, then washed in PBS-BSA $1 \%$ and resuspended in blocking solution (PBS supplemented with 5\% milk) for 10 min. After centrifugation, the cells were permeabilized with Triton X100 0.1\% in PBS-BSA 1\% for four min according to a method described in [17]. The cells were then treated with anti-human Bcl-X $\mathrm{X}_{1}$ or Bak monoclonal antibodies (DBA and Merk KGaA, Darmstadt, Germany, respectively) or control mouse monoclonal antibody and finally with the FITC- conjugated secondary antibody. CD3-, CD19- mononuclear cells were treated with FITC-conjugated anti CD14 (Miltenyi) to assess the purity of the separated monocytes.

To obtain comparable results from the various samples analysed at different times, the sensitivity of the fluorescence detectors was monitored using Calibrite beads (Becton-Dickinson) and an identical setting of the instrument photo-detectors was used throughout the samples acquisition procedure. The fluorescence intensity of each erythrocyte was recorded as arbitrary units on a four-decade logarithmic scale and a geometric mean of the cells fluorescence was calculated by the Cell Quest analysis software.

Ghosts preparation and densitometric analysis of $4.1 \mathrm{a}$ and $4.1 \mathrm{~b}$ proteins

Ghosts were prepared from each subset of red cells by hypotonic lysis, according to a standard procedure [18] and membrane proteins $(12 \mu \mathrm{g}$ per lane in minigels) were analysed by electrophoresis in 7.5\% SDS polyacrylamide gels under reducing conditions according to Laemmli [19]. Gels were stained with Coomassie blue and the ratio between $4.1 \mathrm{a}$ and $4.1 \mathrm{~b}$ proteins was determined by analysing a digital image of the gels with a quantitation software (Scion Image, Scion Corporation, Frederick,MD, USA) [18].

\section{Statistics}

Computer assisted statistical analysis was done by means of the GraphPad software (Graph Pad Software Inc., San Diego, CA, USA). Non-parametric Wilcoxon's matched pairs test was used for the comparison of the RBC subsets cultured under different conditions. Pairs of fluorescence histograms were compared with the Kolmogorov - Smirnov (K.S.) two-samples statistics by means of the Cell Quest software.

\section{Results}

Separation of red cells into age ranked subsets and their survival in vitro

As a preliminary validation of the method for separating RBC into age subsets, we analyzed the ratio of the two isoforms, named a and $b$, of the membrane-skeleton protein 4.1. This ratio is a marker of RBC age independent of cell density or metabolic activity [20]. In agreement with previous data [18], the 4.1a/4.1b ratio increased in parallel with the increase in density of the subsets, i.e. with the age of the subsets (Table 1). Further, we checked the fluorescence of the separated RBCs after loading with calcein-AM which, as already shown, labels viable RBC with intensity that decreases with increasing cell age [16]. As expected, the fluorescence intensity declined progressively from low (young) to middle and high density (middle aged and old) red cells (Fig. 1). On the basis of the validation of the separation procedure, we explored different culture conditions for RBC subsets and analysed their survival in vitro, by determining the percentage of red cells recovered from the cultures at different times.

As a first approach, we used the same culture medium as the one used for human lymphocyte cultures, alone or supplemented with $10 \%$ autologous plasma. In partial agreement with observations by Walsh et al. [21], who studied whole red cell population under the same culture conditions, we found that a lower percentage of young, middle aged and old cells could be recovered from cultures in plasma-free medium than from those with plasma. Furthermore, neocytes showed the lowest survival rate at each time point in both culture mediums $(p<0,01)$ (Fig. $2 \mathrm{a}$ and $\mathrm{b})$. Unexpected was the kinetics of old red cells cultured in 10\% plasma-RPMI: after a decline at day two, likely due to the natural demise of more aged red cells, their percent recovery remained relatively high until day 6 , when $61 \% \pm$ $8,65 \%$ of red cells could still be recovered (Fig. $2 \mathrm{~b}$ ).

To confirm these data we analyzed RBC viability by treating the red cells recovered from the cultures, with calcein-AM. A fast decline in calcein-positive cells, corresponding to the loss of esterase activity and of membrane integrity, was observed in RBC subsets cultured 
Table 1. $4.1 \mathrm{a} / 4.1 \mathrm{~b}$ ratios evaluated on ghosts from low, middle and high density red cells separated from three distinct blood samples (S1, S2, S3). Figures from each blood sample and mean values \pm SD are reported

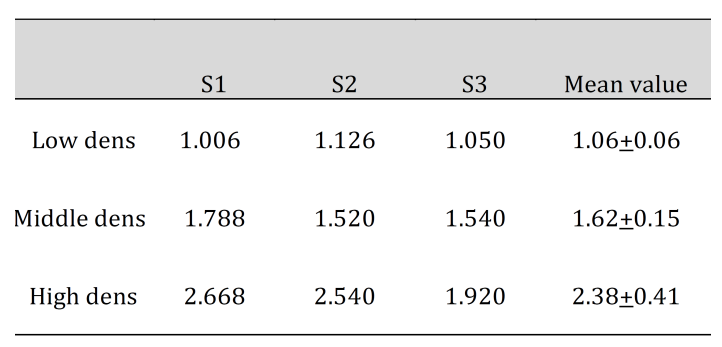

Fig. 1. Calcein fluorescence of age ranked red cell subsets. Overlaid plots of the fluorescence of neocytes (thin line), middle-aged (bold line) old (dashed line) and saponin permeabilised (dotted line) RBC treated with Calein-AM are shown. X-axis: fluorescence intensity, logarithmic scale. Y-axis: relative cell number. Plots are representative from three analyses on distinct blood samples.
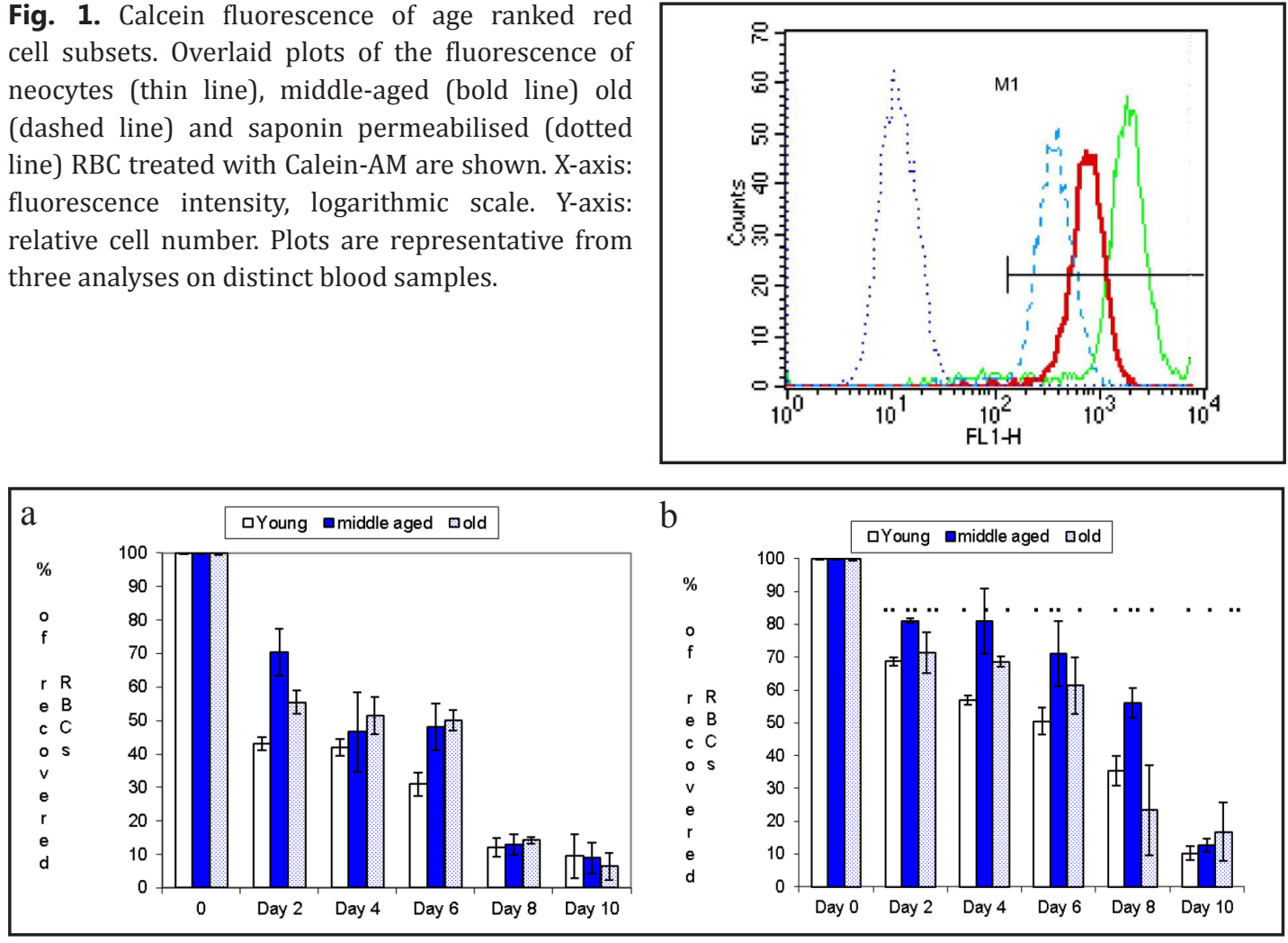

Fig. 2. Survival of neocytes, middle-aged and old red blood cells cultured in vitro in serum free medium (panel a) or in the presence of $10 \%$ autologous plasma (panel b), expressed as percentage of red cells recovered from the cultures at different days. Data \pm SD are reported from four distinct experiments. The survival of each subset in RPMI-10\%plasma was higher than in RPMI alone $(. . p<0,01, . p .<0,05)$.

in plasma-free medium. The decline was slower in red cells incubated in medium enriched with $10 \%$ plasma. However, differences among the subsets emerged, as neocytes showed a faster loss of membrane integrity than the other red cells (Fig. 3, panels a, b, c).

Recently, a default apoptosis pathway has been found and investigated in erythrocytes, which has been named eryptosis by comparison with some features of apoptosis occurring in nucleated cells [22]. Among these features the externalization of PS is regarded as a hallmark of the process [22-24].

In red cells recovered from the cultures, we observed a kinetics of PS externalization consistent with the data on recovery and viability. In plasma-free medium, 10-12\% neocytes showed PS exposure after two days of culture, whereas the other subsets showed a slower kinetics. The addition of autologous plasma slowed down the eryptosis in the neocyte subset, which, however, at day 4 , included a slightly higher percentage of annexin V-binding cells than the other subpopulations $(7.61 \pm 1.5$ vs $5.69 \pm 0.76$ and $0.96 \pm 0.4$,respectively). The 


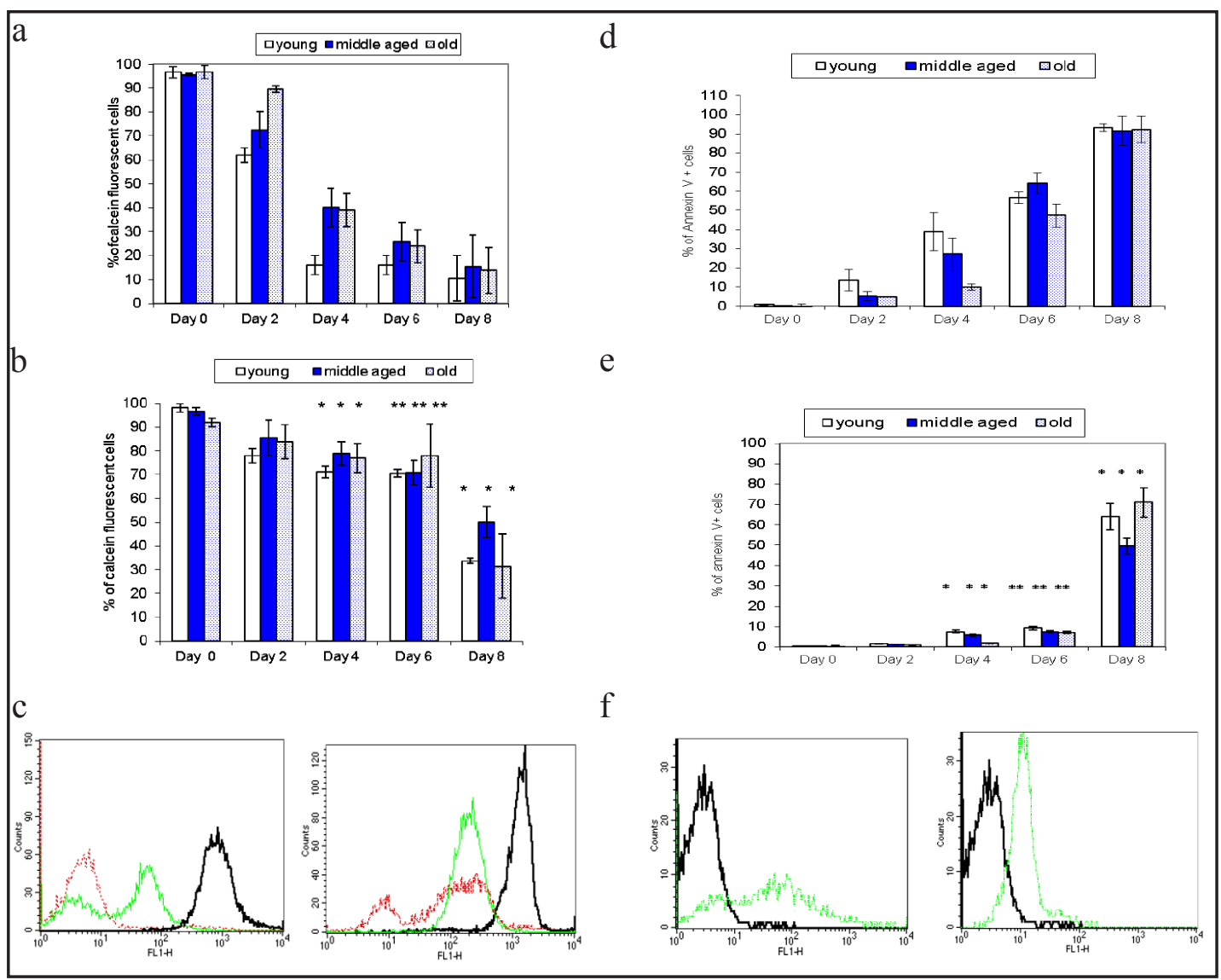

Fig. 3. Viability of neocytes, middle-aged and old red blood cells cultured in serum free medium (panel a, d) or in the presence of $10 \%$ autologous plasma (panel b, e), expressed as percentage of calcein fluorescent (panels a, b) or annexin $\mathrm{V}$ positive (panels d, e) red cells recovered from the cultures at different days. Data \pm SD are reported from three distinct experiments. Statistically significant difference between red cells cultured in $10 \%$ plasma RPMI vs RPMI are indicated $\left({ }^{* *} p<0,01,{ }^{*} p<0,05\right)$. In panels c overlaid plots representing the fluorescence distribution of calcein-AM treated neocytes at day 2 (bold line), 6 (thin line) and 8 (dashed line) of culture in RPMI (left) or plasma enriched medium (right) are shown. In panel $\mathrm{f}$ overlaid plots of the young red cells treated with FITC annexin V after 2 (bold line) or 8 days (dashed line) of culture in RPMI (left) or 10\% plasma RPMI (right) are displayed. K-S two-sample statistics showed significant difference $(p<0.001)$ between the pairs of fluorescent red cells population cultured in plasmaRPMI vs. RPMI alone at days 2, 6 and 8 (panel c) and at day 8 (panel f.)

percentages of PS positive cells increased further at day 6 and at day 8 a high number of red cells bound annexin $\mathrm{V}$ in all the subsets, indicating that a demise process was under way (Fig. 3, panels d, e, f).

To further test this process, we analysed the expression of three membrane molecules, which are partially lost during in vivo senescence of erythrocytes, due to a physiological turn over or to adaptive response to environmental cues, i.e. CD55, CD59 and CD47 [6, 25, 26].

CD55 and CD59 are glycosylphosphatidyl-anchored membrane proteins, which protect red cells from activated complement [27]. In the mouse, CD47 is involved in the recognition and inhibition of RBC phagocytosis by macrophages [28, 29]. Whether CD47 in human red cells plays a similar role is still debated [30-33]. After six days in culture, a partial loss of CD55 (Fig. 4, panel a) was observed in the survived neocytes as compared to the neocytes at the beginning of the culture $(p<0.001)$, while the slight decrease in the expression of CD47 and CD59 (Fig. 4, panels b and c) was less significant ( $p=0.05$, and $p=0.01$, respectively). 

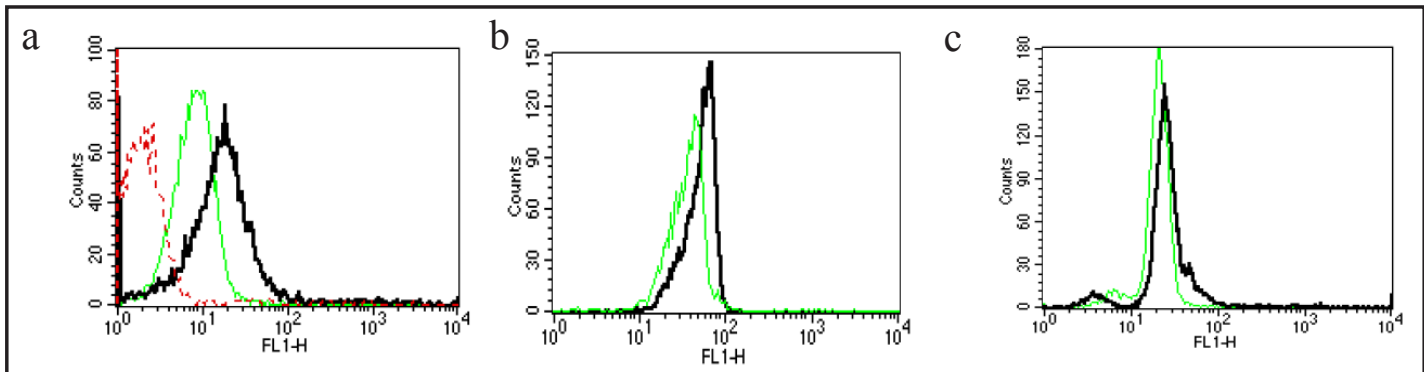

Fig. 4. Expression of CD55 (a), CD59 (b) and CD47 (c) by neocytes at the beginning (bold line) and by those survived after 6 days (thin line) of in vitro culture in RPMI-10\% autologous plasma. In the CD55 panel the dashed line indicates the fluorescence distribution of red cells treated with an irrelevant control monoclonal antibody. K-S two-sample statistics showed significant difference $(p<0.001)$ between the pair of fluorescent CD55+ RBCs populations examined. Data are representative of two distinct analyses.

\section{Effect of erythropoietin on RBC subsets cultured in vitro}

In plasma-enriched culture medium EPO concentration is very low (about $1 / 5$ of the mean level in circulating blood, which is $10-15 \mathrm{mIU} / \mathrm{ml}$ in normal subjects). Thereby, to investigate a possible protective role of erythropoietin on red cells cultured in vitro, we incubated age-ranked red cells in a medium enriched with $10 \%$ plasma and human recombinant erythropoietin at concentrations ranging from physiological to higher doses, similar to those of the therapeutical range (from 0.01 to $10 \mathrm{IU} / \mathrm{ml}$ ). Then, we studied the possible EPO-mediated rescue from death starting after 6 days of culture, when, on the basis of cells recovery data and phenotypic features, a detectable death process could be observed in the cultures when no exogenous EPO was added (see Fig. 2-4).

As shown in Fig. 5a, concentrations close to the physiological ones ( 0.05 and, to a higher extent, $0.01 \mathrm{IU} / \mathrm{ml}$ ) favored the survival of neocytes. In particular, at each time point, the percentage of red cells recovered from cultures with $0.01 \mathrm{IU} / \mathrm{ml} \mathrm{EPO}$, were significantly higher than those measured in control cultures $(\mathrm{p}<0.05)$. In contrast, at EPO concentrations above those physiological $(0.5,1.0$, and $10.0 \mathrm{IU} / \mathrm{ml})$ a lower number of young RBCs was recovered from the culture and, correspondingly, the survival, measured as percent of calcein- and PSpositive cells also decreased (data not shown). The pro-survival effect of $0.01 \mathrm{IU} / \mathrm{ml} \mathrm{EPO}$ was amplified by the presence of autologous adherent monocytes, which promoted an even higher survival rate of neocytes, as compared with the cultures without adherent cells (Fig. $5 b)$.Furthermore, even with no EPO addition, monocytes per se prolonged the survival of neocytes, as indicated by the percentage of recovered neocytes at day 12 , which was higher than in the absence of monocytes ( $42 \pm 4.5 \%$ vs $10 \pm 4 \%, p=0.05$ ), see Fig. 5 panels a and $b$, "no EPO" bars), and by the percent of calcein positive (78 $\pm 18 \%$ vs $41 \pm 22 \%)$ and the lower number of annexin $\mathrm{V}$ binding red cells $(20 \pm 6 \%$ vs $52 \pm 7.8 \%)$.

The effect of adherent cells was impaired when the latter cells were replaced with the supernatant obtained from $36 \mathrm{~h}$ cultures of adherent monocytes, since the survival potential of neocytes decreased significantly when compared to those incubated with monocytes ( $p \leq$ 0.05) (Fig. 5c).

On the other RBC subsets, EPO failed to increase the survival, both at high concentrations (1-10 IU/ml, data not shown) and at low doses even when red cells were co-cultured with adherent cells (Fig. 5 d,e).

\section{Sensitivity of neocytes to survival signals}

In a previous work, Walsh et al. showed that in red cells cultured in vitro, the balance between survival and death can be regulated by the anti- and pro-apoptotic proteins $\mathrm{Bcl}-\mathrm{X}_{\mathrm{L}}$ and Bak, respectively. Both proteins are expressed on the membrane of red cells and their regulatory potential has been shown by the death of red cells, when they were cultured in vitro with a Bak derived peptide fused to an internalization sequence and able to interact with Bcl-X ${ }_{1}[21]$. 


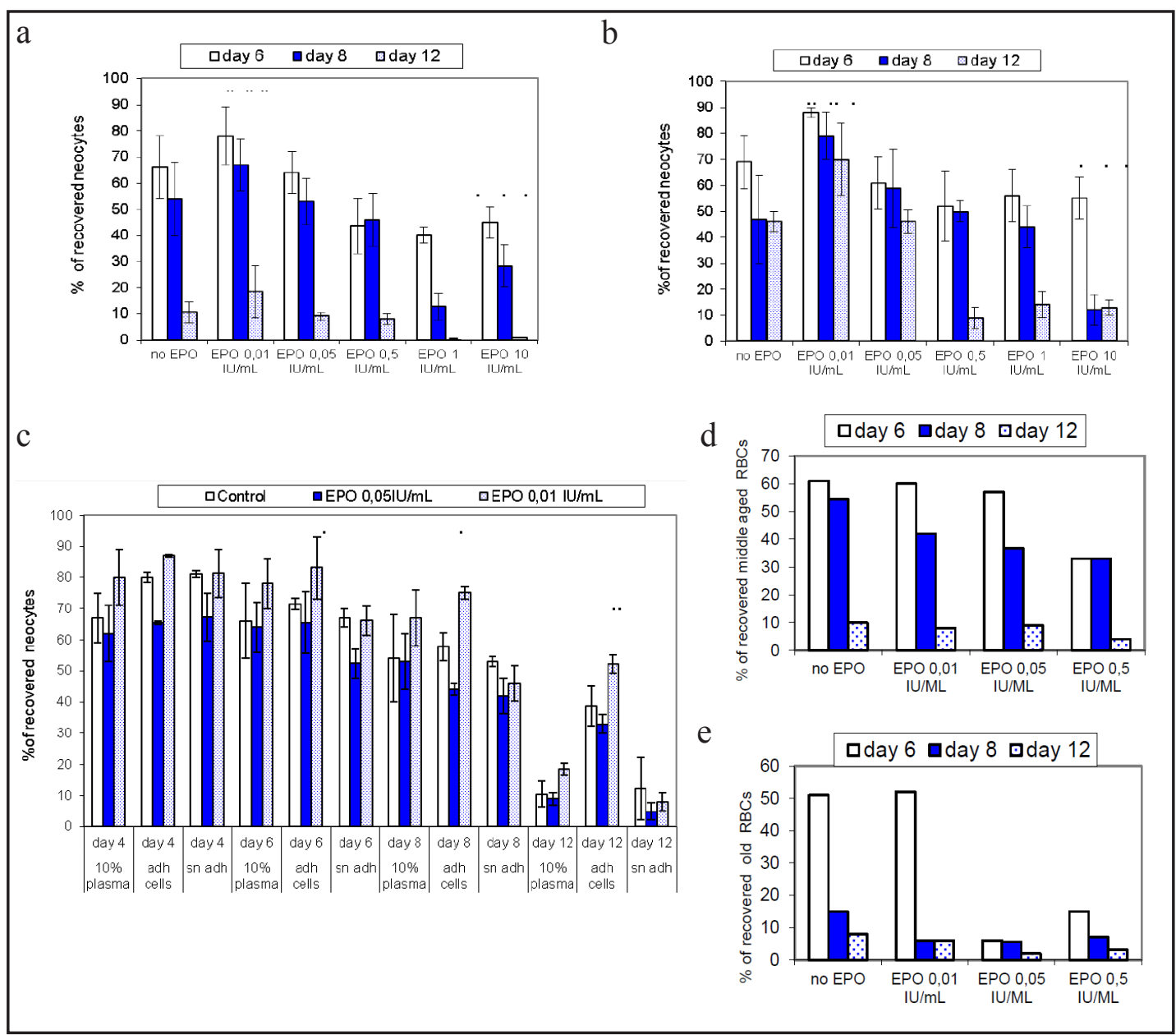

Fig. 5. Survival kinetics of neocytes cultured with EPO, with $10 \%$ autologous plasma (panel a), in the presence of autologous CD14+ adherent cells (panel b) or in the presence of supernatant of the same cells cultured for 36 hours (panel c). Mean values \pm SD from three distinct experiments are shown. In panel a and $\mathrm{b}$, the neocytes survival variations after culture with EPO or EPO and monocytes versus control, and in panel $\mathrm{c}$ the different pro-survival effects of EPO $10 \mathrm{mIU} / \mathrm{ml}$ and monocytes versus EPO $10 \mathrm{mIU} / \mathrm{ml}$ and supernatant with statistical significance, are indicated(.. $p<0,01, . p .<0,05)$. In panels $\mathrm{d}$ and e the effect of EPO on middle aged (panel d) and old (panel e) red blood cells incubated with 10\% autologous plasma and adherent cells is shown. A representative experiment is shown out of two.

The different response of the red cells subsets to the culture conditions raised the possibility that these two apoptosis regulators were differentially expressed in RBCs subsets of different age.

A low expression of these proteins in red cells and a modest difference between the subsets was visualized by western blotting of electrophoresed red cells proteins (data not shown). However, by flow cytometry, which analyzes single cells, we could observe and quantitatively determine a higher level of expression by neocytes with respect to the other subsets, both in term of percentage and intensity fluorescence of positive cells (Fig. 6a and b).

\section{Discussion}

After maturation from erythroid precursors, the life of red cells in circulating blood can be seen as a delayed apoptosis, which is timely regulated and associated to molecular 


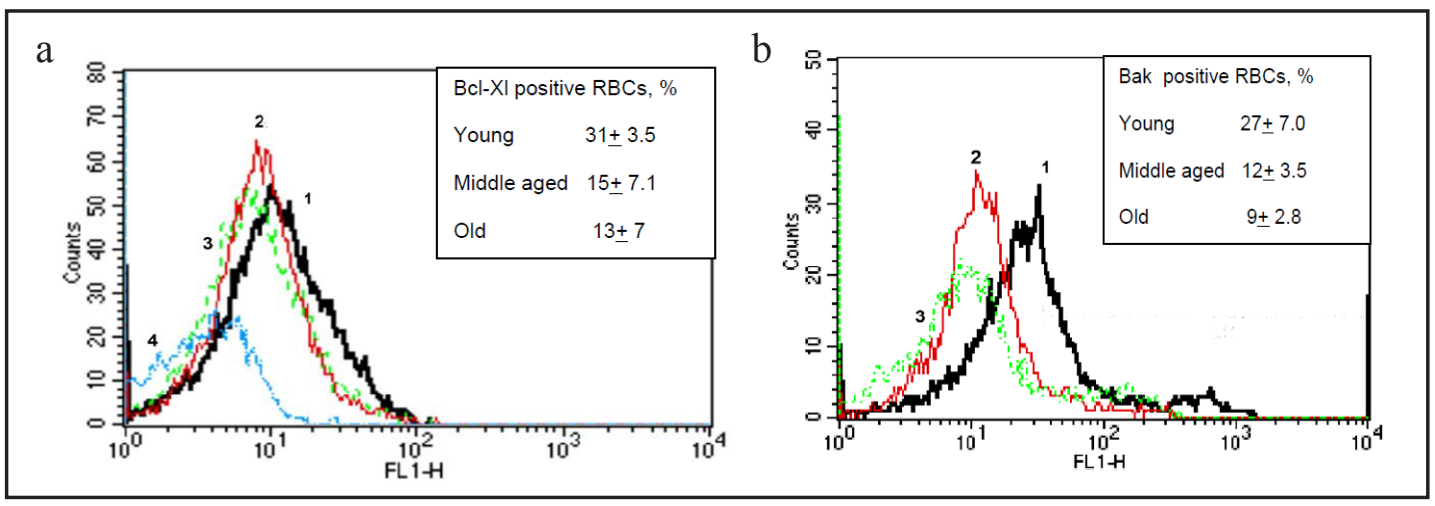

Fig. 6. Flow cytometry analysis of expression of Bcl-xl (panel a) and Bak (panel b) by neocytes (bold solid line, n.1), middle aged (solid line, n.2), old (dashed line, n.3) red cells. In panel a, line n.4 represents the fluorescence distribution of RBCs treated with a control monoclonal antibody. KS two sample statistics indicated significant $(p<0.01)$ difference between the neocytes and middle aged or old fluorescent populations. Representative data out of three separate experiments are shown. In the panels, the insets report the average percent of the positive red cells which were identified by gating out the RBCs population treated with the control antibody.

changes, that ultimately leads to senescence, eryptosis and disposal [21, 34]. In this view, we should expect RBC mass reduction by means of an accelerated destruction of old and degenerated, not neocytes, as it seems to occur over the neocytolytic process [4]. In some cases neocytolysis could be partially due to the intrinsic properties of those neocytes generated from precursors that were exposed to pathological or environmental cues such as fluctuations in EPO plasma levels and blood composition and ionic balance, as occur in anemic uremic patients [35], or the increase of EPO production in healthy people exposed to hypoxia [5], that could lead to release of red cells defective or not adapted to normoxia $[6,13]$. In these cases the clearance of neocytes could be accounted for by the need to eliminate the red cells damaged or endowed with features not fit to their function in a normal environment.

However, the clearance of red cells and in particular of neocytes generated in normogravity, which occurs during the first days of spaceflight $[7,8,12]$, or after EPO doping [11], are less likely due to specific features of defective red cells. It is more likely that their removal from circulating blood is strictly linked to EPO decline. The complexity of neocytolysis investigation in vivo and the multiple forms of neocytolysis so far described, which fail to provide univocal interpretation keys for the process [13] prompted us to design an experimental system in vitro where the relationship between EPO and red cells separated into age related subsets could be analyzed with no interference by other factors, such as alterations in the molecular components of red cells due to hypoxia. The validation of the RBC separation procedure into age ranked subsets enabled us to comparatively analyze the progressive decline of viability of the subsets in vitro cultured and to provide an in vitro model to assay their survival potential in the absence or presence of EPO. When no exogenous EPO was added to the culture medium, we observed a lower survival rate of neocytes as compared to middle aged and old RBCs, either when they were cultured in RPMI medium or in RPMI supplemented with platelet-depleted autologous plasma. The loss of viability was associated to a senescence process, indicated by a decrease of CD55 expression [6, 25, 26], and to eryptosis, as suggested by externalization of PS, which is a marker of this process [22-24].

Previously, Walsh et al. have already shown that survival of erythrocytes cultured in vitro is increased by the presence of plasma [21], although under the experimental condition described in the article, RBCs remained viable for more days (10 and 15 days when cultured in medium or in medium supplemented with $10 \%$ plasma, respectively). However, the study investigated the whole population of RBCs, separated from mononuclear leukocytes 
by centrifugation on Ficoll gradient [21]. We isolated RBCs by a different procedure and separated and analyzed RBC subsets, then our results are not comparable to those reported by Walsh et al. The two steps of our separation method, (filtration of red cells followed by density centrifugation) ensured that the percentage of polymorphonuclear and mononuclear leukocytes contaminating the subsets (and possibly changing their survival capability) was very low [15]. The issue of leukocytes contamination in our study was not trivial since, as shown from the data here reported, monocytes seem to be able to support the in vitro survival of young RBCs either alone or in synergy with EPO (see Fig. 5 b).

The neocyte viability increased when EPO was added to the culture medium at a relatively low (physiological) concentration. This observation could suggest an EPO receptor on neocytes, as already reported by Mihov et al. [36]. They found the receptor in mouse red cells, especially in the youngest ones, and showed that incubation of red cells with EPO for 120 min activates endothelial nitric oxide synthase and controls the intracellular redox state [36].

Surprising is the low survival rate of human neocytes and of the other red cells subsets cultured with high doses of EPO $(0.5,1.0$ or $10.0 \mathrm{IU} / \mathrm{ml})$, but these data are in agreement with those observed in transgenic mice overexpressing EPO, where red cells survival was impaired and sensitivity to eryptotic stimuli enhanced [37]. Furthermore, as shown by Mihov et al. [36] at high concentration (1 and $100 \mathrm{IU} / \mathrm{ml}$ ), EPO may play a dual role as pro- or anti-oxidant, depending on the availability of L-arginine. It is likely that in the long term in vitro cultures, unphysiologically high doses of EPO in combination with a decreased availability of L-arginine could change the redox state of red cells, making them more prone to eryptosis.

Finally, it seems that, besides EPO, the in vitro lifespan of neocytes is modulated by other factors, since monocytes are able to enhance the effects of the latter hormone. This likely occurs through direct contact between adherent cells and neocytes, or thanks to paracrine trophic factors, as suggested by the low efficacy of monocyte supernatants.

We cannot rule out a direct effect of EPO on monocytes, which would induce the release of trophic factor(s). Indeed, EPO targets directly murine macrophages in vivo and in vitro, by enhancing their pro-inflammatory activity and function, and monocyte-derived dendritic cells express EPO receptors [38, 39]. However, since adherent cells themselves are able to support the survival of neocytes, even in the absence of EPO, (see Fig. 5), it is reasonable to conceive a specific protective role played by adherent monocytes on these red cells, which could be reinforced by EPO.

Recent studies have demonstrated a synergy between bone marrow CD169+ human macrophages and EPO in supporting steady state and stress erythropoiesis, such as the one occurring in polycythemia vera and beta-thalassemia [40,41]. Since these researches were focused on erythroid precursors, any parallel with our experimental system is difficult to propose. Some clues to understand the molecular mechanisms of neocytes survival could come from dissecting the molecular mechanisms involving the two molecules that sense the presence of survival/death factors, i.e. Bcl- $\mathrm{X}_{1}$ and Bak [21], and from further investigation on the EPO mediated control of the cellular redox state [36].

In conclusion, although, as already suggested [13], each form of neocytolysis in vivo needs an investigative approach more focussed on the cellular and molecular details of the process, this study, with the limitations of the in vitro analyses, provides a framework where a common interpretation at cellular level can be proposed, at least for those cases where haemolysis affect neocytes generated from precursors which matured in normal conditions.

In fact, our observations on the survival of neocytes suggest that they are more sensitive than the other red cells to presence or absence of survival factors and indicate that EPO could play a role not only in the maturation of erythroid precursors but also in the control of young, mature red cells lifespan, possibly synergizing with other soluble or cell-mediated factors. 


\section{Disclosure Statement}

The Authors do not have any conflict of interest.

\section{Acknowledgements}

We are grateful to dr. Angela Michelutti for discussions and for help in the flow cytometry experiments. This work was supported by the "Ministero dell'Università e della Ricerca", Italy, with PRIN2008 funds to G.M. and A.R.

\section{References}

1 Beutler E: Production and Destruction of Erythrocytes; in Beutler E, Coller M, Lichtmann M, Kipps T, Seligshon U (eds): Williams Haematology VIth edition, New York, Mc-Graw-Hill, 2001, pp 355-368.

2 Weatherall DJ:The thalassemias; in Beutler E, Coller M, Lichtmann M, Kipps T, Seligshon U (eds): Williams Haematology VIth edition, New York, Mc-Graw-Hill, 2001, pp.547- 580.

3 Beutler E:The sickle cell diseases and related disorders; in: Beutler E, Coller M, Lichtmann M, Kipps T, Seligshon U (eds): Williams Haematology VIth edition, New York, Mc-Graw-Hill, 2001, pp 581-606.

4 Alfrey CP, Rice L, Udden MM, Driscoll TB: Neocytolysis: physiological down-regulator of red-cell mass. Lancet 1997;349:1389-1390.

-5 Rice L, Ruiz W, Driscoll T, Whitley CE, Tapia R, Hachey DL, Gonzales GF, Alfrey CP: Neocytolysis on descent from altitude: a newly recognized mechanism for the control of red cell mass. Ann Intern Med 2001;134:652-656.

6 Risso A, Turello M, Biffoni F, Antonutto G: Red blood cells senescence and neocytolysis in humans after high altitude acclimatisation. Blood Cells Mol Dis 2007; 38:83-92.

7 Alfrey CP, Udden MM, Leach-Huntoon C, Driscoll T Pickett MH: Control of the red blood cell mass in spaceflight. J Appl Physiol 1996;81:98-104.

8 Rice L, Alfrey CP: Modulation of red cell mass by neocytolysis in space and on Earth. Pflugers Arch 2000;441:S R91-94.

-9 Rice L, Alfrey CP, Driscoll T, Whitley CE, Hachey DL, Suki W: Neocytolysis contributes to the anemia of renal disease. Am J Kidney Dis 1999;33:59-62.

10 Rice L, Alfrey CP: The negative regulation of red cell mass by neocytolysis: physiologic and pathophysiologic manifestations. Cell Physiol Biochem 2005; 15: 245-250

11 Chang CC, Chen Y, Modi K, Awar O, Alfrey C, Rice L: Changes of red blood cell surface markers in a blood doping model of neocytolysis. J Investig Med 2009;57:650-654.

12 Risso A, Turello M, Antonutto G: Effects of spaceflight on erythropoiesis: a study on neocytolysis. J Grav Physiol 2008;15:201-202.

13 Risso A, Ciana A, Achilli C, Antonutto G, Minetti G: Neocytolysis: none, one or many? A reappraisal and future perspectives. Frontiers in Physiology. Memb Physiol Memb Biophys 2014, doi:10.3389/ fphys.2014.00054

14 Trial J, Rice L, Alfrey CP: Erythropoietin withdrawal alters interactions between young red blood cells, splenic endothelial cells, and macrophages: an in vitro model of neocytolysis. J Investig Med 2001;49:335345 .

15 Achilli C, Ciana A, Balduini C, Risso A, Minetti G: Application of gelatin zymography for evaluating low levels of contaminating neutrophils in red blood cell samples. Anal Biochem 2012;409:296-297

- 16 Bratosin D, Mitrofan L, Palii C, Estaquier J, Montreuil J: Novel fluorescence assay using calcein-AM for the determination of human erythrocyte viability and aging. Cytometry 2005;66:78-84.

17 Davis BH, Davis KT: Enumeration of fetal red blood cells, F cells, and F reticulocytes in human blood. Curr Protoc Cytom. Chapter 6: Unit 6.17. 2004. 
18 Minetti G, Ciana A, Profumo A, Zappa M, Vercellati C, Zanella A, Arduini A, Brovelli A: Cell age-related monovalent cations content and density changes in stored human erythrocytes. Biochim Biophys Acta 2001;1527:149-155.

19 Laemmli UK: Cleavage of structural proteins during the assembly of the head of bacteriophage T4. Nature 1970;227:680-685

20 Robinson NE, Robinson AB: Deamidation of Asparaginyl and Glutaminyl Residues in Peptides and Proteins in Molecular Clocks, Cave Junction, OR, Althouse Press, 2004.

21 Walsh M, Lutz RJ, Cotter TG, O'Connor R: Erythrocyte survival is promoted by plasma and suppressed by a Bak-derived BH3 peptide that interacts with membrane-associated Bcl-X(L). Blood 2002;99:3439-3448.

-22 Lang E, Qadri SM, Lang F: Killing me softly-Suicidal erythrocyte death. Int J Biochem Cell Biol 2012;44:1236-1244.

23 Connor J, Pak CC, and Schroit AJ: Exposure of phosphatidylserine in the outer Leaflet of human red blood cells. Relationship to cell density, cell age, and clearance by mononuclear cells. J Biol Chem1994;269:23992404.

24 Boas FE, Forman L, Beutler E: Phosphatidylserine exposure and red cell viability in red cell aging and in hemolytic anemia. Proc Natl Acad Sci USA 1998;95:3077-3081.

25 Pascual M, Danielsson C, Steiger G, Schifferli JA: Proteolytic cleavage of CR1 on human erythrocytes in vivo: evidence for enhanced cleavage in AIDS. Eur J Immunol 1994;24:702-708.

-26 Willekens FL, Werre JM, Groenen-Döpp YA, Roerdinkholder-Stoelwinder B, de Pauw B, Bosman GJ: Erythrocyte vesiculation: a self-protective mechanism? Br J Haematol 2008;141:549-556.

27 http://www.immunologylink.com/cdantigen.html

-28 Oldenborg PA, Zheleznyak A, Fang YF, Lagenaur CF, Gresham HD, Lindberg FP: Role of CD47 as a marker of self on red blood cells. Science 2000;288:2051-2054.

-29 Oldenborg PA, Gresham HD, Chen Y, Izui S, Lindberg FP: Lethal autoimmune haemolytic anemia in CD47deficient non obese diabetic (NOD) mice. Blood 2002;99:3500-3504.

-30 Tsai RK, Discher DE: Inhibition of "self" engulfment through deactivation of myosin-II at the phagocytic synapse between human cells. J Cell Biol 2008;180:989-1003.

- 31 Oldenborg PA: Role of CD47 in erythroid cells and in autoimmunity. Leuk Lymphoma 2004;45:1319-1327.

-32 Tsai RK, Rodriguez PL, Discher DE: Self-inhibition of phagocytosis: the affinity of 'marker of self' CD47 for SIRPalpha dictates potency of inhibition but only at low expression level. Blood Cells Mol Dis 2010;45:6774.

33 Burger P, Hilarius-Stokman P, de Korte D, van den Berg TK, van Bruggen R: CD47 functions as a molecular switch for erythrocyte phagocytosis. Blood 2012;119:5512-5521.

-34 Bratosin D, Estaquier J, Slomianny C, Tissier JP, Quatannens B, Bulai T, Mitrofan L, Marinescu A, Trandaburu I, Ameisen JC, Montreuil J: Programmed cell death in mature erythrocytes: a model for investigating death effector pathways operating in the absence of mitochondria. Cell Death Diff 2001;8:1143-1156.

-35 Susantitaphong P, Sewaralthahab K, Balk EM, Jaber BL, Madias NE: Short- and Long-Term Effects of Alkali Therapy in Chronic Kidney Disease: A Systematic Review. Am J Nephrol 2012;35:540-547.

-36 Mihov D, Vogel J, Gassmann M, Bogdanova A: Erythropoietin activates nitric oxide synthase in murine erythrocytes. Am J Physiol Cell Physiol 2009;297:C378-388.

- 37 Föller M, Kasinathan RS, Koka S, Huber SM, Schuler B, Vogel J, Gassmann M, Lang F: Enhanced susceptibility to suicidal death of erythrocytes from transgenic mice overexpressing erythropoietin. Am J Physiol Regul Integr Comp Physiol 2007;293:R1127-1134.

- 38 Lifshitz L, Prutchi-Sagiv S, Avneon M, Gassmann M, Mittelman M, Neumann D: Non-erythroid activities of erythropoietin: Functional effects on murine dendritic cells. Mol Immunol 2009;46:713-721.

-39 Lifshitz L, Tabak G, Gassmann M, Mittelman M, and Neumann D: Macrophages as novel target cells for erythropoietin. Haematologica 2010;95:1823-1831.

-40 Chow A, Huggins M, Ahmed J, Hashimoto D, Lucas D, Kunisaki Y, Pinho S, Leboeuf M, Noizat C, van Rooijen N, Tanaka M, Zhao ZJ, Bergman A, Merad M, Frenette PS: CD169+ macrophages provide a niche promoting erythropoiesis under homeostasis and stress. Nat Med 2013;19:429-436.

41 Ramos P, Casu C, Gardenghi S, Breda L, Crielaard BJ, Guy E, Marongiu MF, Gupta R, Levine RL, Abdel-Wahab O, Ebert BL, Van Rooijen N, Ghaffari S, Grady RW, Giardina PJ, Rivella S: Macrophages support pathological erythropoiesis in polycythemia vera and $\beta$-thalassemia. Nat Med2013;19:437-445. 